\author{
EDWARD KLIMASARA \\ ANDRZEJ P. WIERZBICKI
}

\title{
EXAMPLES
}

\section{OF MULTIPLE CRITERIA RANKING IN DESIGN OF CELLULAR NETWORKS OF MOBILE TELECOMMUNICATION}

\begin{abstract}
This paper addresses the planning and design of contemporary networks of mobile telecommunication where an existing network is subject to far-reaching development and modification and, thus, an evolution with diverse requirements of users and a diverse density of network cells. This leads to considering the diverse variants of network designs. When several variants of network designs are available, an investor might ask for a ranking of these variants. The investor is obviously not bound by the results of such a ranking and might select a variant that is not the highest in the ranking, but an objectified ranking might help in the selection. Therefore, the paper presents a way of computing and examples of ranking objectified multiple criteria and (if possible) not requiring the determination of weighting coefficients.
\end{abstract}

Keywords design of cellular networks, network evolution, variants of network designs, multiple criteria ranking of network designs, objectified ranking

Citation Computer Science 19(1) 2018: 99-112 


\section{Introduction. Evolution of cellular networks}

The requirements of mobile telecommunication networks constantly change and grow; a result of the integration of cellular networks with the Internet and television, the development of diverse network services (starting with e-banking), and finally the increase of requirements of business users for whom mobile telecommunication has become a fundamental tool. Therefore, the classical cellular telecommunication networks change, as they are subject to long-term evolution. This evolution also concerns the technologies used in those networks: they must anticipate the changes of the requirements of users. Hence, one of the most-popular technologies is called LTE (long-term evolution) $[1,5,11]$.

Classical cellular telecommunication networks are built in the form of a honeycomb containing alike hexagonal cells with antennas (base stations) located in the center of the cells. Due to this evolution, they are enhanced by the addition of more base stations, sometimes also in the form of a local honeycomb with smaller cells. The placement of these base stations is particularly dense in business centers, where the cells can correspond to separate buildings or even large rooms [4]. The cells of the honeycomb are often deformed, particularly when directional antennas are used along with omni-directional ones. In this paper, we assume (for simplicity) that networks are designed as honeycombs with omni-directional antennas of diverse densities.

The design of such a network - whether as a new one or as a modification of an existing one - is obviously based on a maximization of the expected profit with a restricted or minimized investment cost. However, such a network must also take into account a number of other technical or economic parameters, such as network capacity, its coverage, operation costs compared to the initial investment cost, etc. $[7,8,9,10,13]$.

If profit is not a dominating criterion, then the selection of the best project is actually a multiple-criteria optimization problem [3]. While avoiding rather-complex algorithms of such an optimization, the designers of a new or modified network usually prepare several variants of network projects. A review of such variants enables us to select a variant that appears to be best for the investor. However, it is possible to support the investor in such a selection by presenting not only a list of design variants but also a multiple criteria ranking of these variants to her/him. Until now, typical methods of ranking were based on a weighted sum of the criteria employed, with weighting coefficients specified by experts or the investor. However, such rankings give highly subjective results; the purpose of this paper is to examine the possibility of objectifying such rankings, following a method proposed in (Wierzbicki 2008) [12]. Such an objectification avoids specifying the weighting coefficients, replacing them with aspiration and reservation levels computed from the data contained in the description of the design variants. Obviously, the investor might choose a variant not necessarily from the top of the ranking, but holding such a ranking helps enrich the decision process. 
The goal of this paper is to illustrate some possible ranking procedures. We first assume some exemplary variants of network designs. To simplify the presentation, we assume that the variants concern building a network from scratch, not a modification of an existing network. However, the proposed methods can obviously also be applied for rankings of the variants of network modification. The proposed ranking methods relate to an objectified ranking; i.e., such a ranking that results only from the data of the problem and does not require an assumption of the weighting coefficients. Such a ranking method was also called objective ranking [12], but a fully objective ranking does not exist since the selection of a ranking method is a subjective decision. Actually, since network investments are highly profitable (particularly in concentrated areas with a large number of business users), the profit criterion might turn out to be dominating. However, it might be useful to compare or combine a ranking resulting from this criterion with an objectified multiple criteria ranking.

\section{Criteria of quality of cellular network design}

There are many parameters that can serve as criteria for the quality of network design. Among them are the contention ratio, coverage, delay budget, error loss rate, expected number of users, expected yearly income, handover, interference, investment costs, latency, network capacity, number of cells, operating costs, performance, QoS various types of services, etc. However, we restrict this list to a selected number of parameters in our examples while avoiding those that do not change significantly between the considered variants of network design. Therefore, we assume the following criteria of quality in a cellular network's design:

- network capacity,

- expected number of users,

- expected yearly income,

- coverage,

- number of cells,

- interference,

- contention ratio (the number of users compared to network capacity),

- investment costs (CAPEX - capital expenditures),

- operating costs (OPEX - operating expenditures).

Network capacity is the maximum number of users utilizing the network at the same time.

Expected number of users is the potential number of users utilizing the network at any time.

Expected yearly income depends on the number and type of users; we assume below that about $30 \%$ of the population on the area considered (i.e., about 55,000 people) will be utilizing the network. For simplicity, we assume that the yearly income from an average customer (the average of private and business customers) will amount to ca. $50 \$$ monthly. 
Coverage is defined as the percentage of the respective area that allows for network communication.

Number of cells is the number of cells (or antennas) in the proposed network.

Interference is an indicator of the overlap of radio waves from neighboring antennas on the junction of cells. This might result in disturbances that annoy the user of a cellular network. On one hand, interference increases with the number of cells in a given area; but on the other hand, the number of cells grows to serve a growing number of users. Therefore, diverse technologies that limit interference are used. We assume that such technologies are included in the design of the network and, thus, the impact of interference is small (concerning only $1 \%$ of the area considered, although it grows with the number and density of the cells).

Contention ratio indicates a possible overload of the network if all users were to connect to the network at the same time. For example, a contention ratio of $50: 1$ would mean that 50 users would like to share the bandwidth designed to serve 1 user. Obviously, a high contention ratio indicates a low quality of service.

Investment costs are the costs of building the network.

Operating costs are the yearly costs of maintaining the network.

Indicators such as the network capacity, coverage, expected number of users, and expected yearly income are to be maximized, while the number of cells, investment costs, operating costs, and interference are to be minimized. Similarly, the contention ratio should be minimized if possible; if it is growing, the quality of the service deteriorates.

\section{Examples of design variants of cellular network}

In this point, we present several variants of an example of cellular network design. Real field data from an operating cellular network is considered a business secret of the firm(s) that own the network. Experimental networks have data far different than real field data. Thus, we assume data close to realistic cases in the following examples. The following assumptions are made for these examples.

- A contemporary technology such as LTE was selected.

- The network will be built on a lowland area of 1250 square kilometers.

- One cell can simultaneously serve 300 users with a maximal throughput downlink of $300 \mathrm{MB} / \mathrm{s}$ and uplink of $50 \mathrm{MB} / \mathrm{s}$.

- The service will have mixed character: voice, data, video, etc.

- The number of people living in the area is 170,000 . At least $30 \%$ of them will use the network services.

- The coverage will exceed $70 \%$ of the area involved.

- The investment cost of one cell is $54,000 \$$ on average (smaller cells are cheaper, and larger ones are more expensive).

- The operation cost of one cell is $10,800 \$$ per year on average. A return on the investment costs is expected in five years. 


\section{Variant 1}

The density of population is not uniform in the area considered. The area consists of a rural part with a population density of 50 persons per square kilometer and a city with an area of 50 square kilometers and with a population density of 2500 persons per square kilometer. A possible localization of the network cells is presented in Figure 1, where blue indicates cells in the city, and black - cells in the rural area.

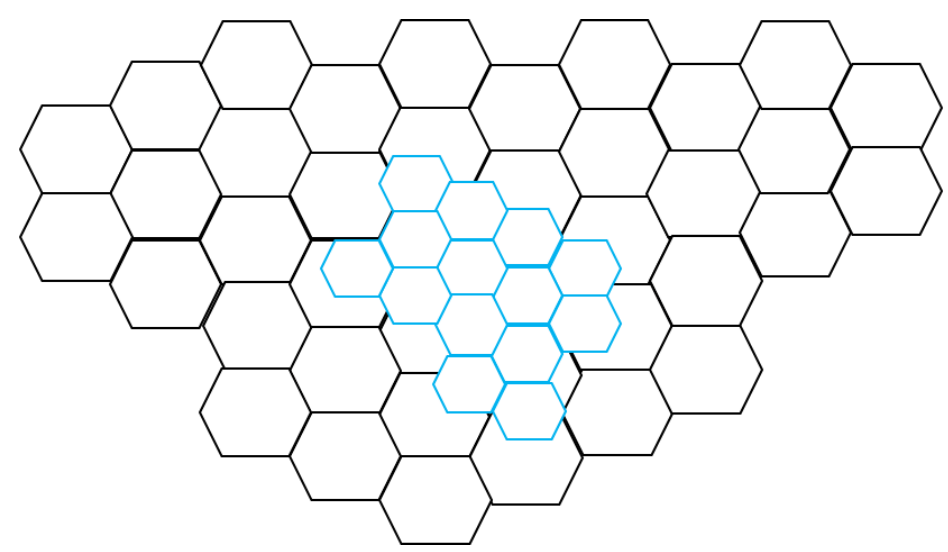

Figure 1. Localization of network cells in city and in rural area

Thus, the rural area amounts to 1200 square kilometers. If we assume that one cell covers ca. 30 square kilometers, so 40 cells should suffice. One cell might serve up to 50 x $30=1500$ customers. Since one cell can serve only 300 customers at the same time, the contention ratio of 5:1 is not excessive. The edges of the area or gaps between the cells might be not covered by the network; hence, the assumed coverage is $96 \%$. The city area is 50 square kilometers, but more smaller cells are necessary. If we assume 50 cells with 2500 customers per cell, then the contention ratio rises above 8:1 (but, this is still admissible). Because of the large number of small cells, the interference is $1 \%$.

\section{Variant 2}

Even in the rural area, the density of the population might be not uniform. Besides the rural area of 1050 square kilometers with a population of density 50 persons per square kilometer, we also take into account a suburban area with a population density of 250 persons per square kilometer and with an area of 150 square kilometers in this variant. As in Variant 1, the city has a population density of 2500 persons per square kilometer and an area of 50 square kilometers. The localization of cells in this variant is presented in Figure 2, where blue represents the cells in the city, green - cells in the suburban area, and black - cells in the rural area.

To cover the rural area, we need 1050:30=35 cells here (if one cells covers $30 \mathrm{~km}^{2}$ ). As in Variant 1, the contention ratio of $5: 1$ is not excessive. The city area is covered by 50 cells (also like Variant 1), which results in a contention ratio of 
above 8 . The suburban area of $150 \mathrm{~km}^{2}$ is covered by 30 cells, each covering $5 \mathrm{~km}^{2}$ and serving 1250 customers, which results in a rather low contention ratio of $4: 1$. The coverage is about $96 \%$, and the interference is $1.1 \%$.

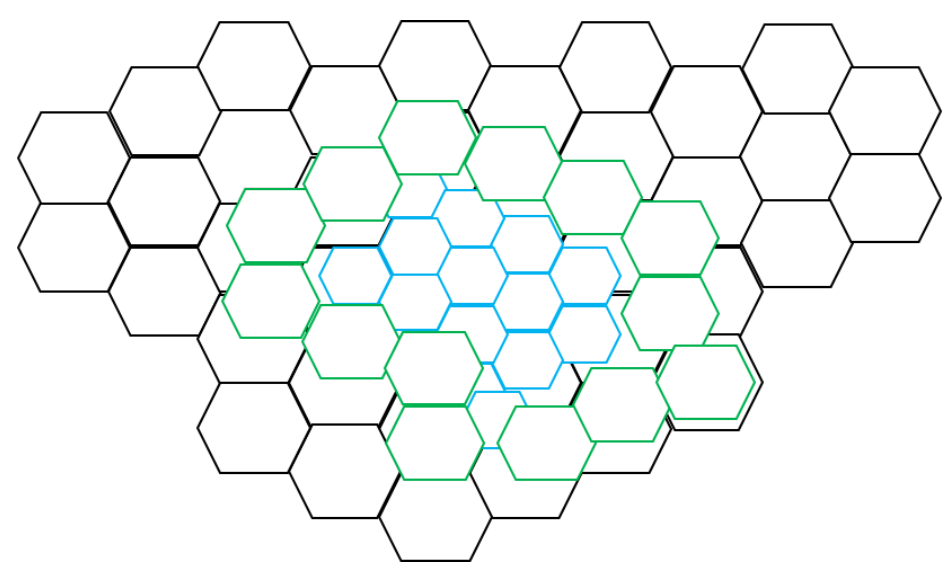

Figure 2. Localization of cells in city, suburbs, and rural areas

\section{Variant 3}

We assume here that Variant 2 is enhanced by a business center in the city with an area of 1 square $\mathrm{km}$ and a large density of users (5000 persons $/ \mathrm{km}^{2}$ ). To serve the business center, 4 new cells are added, each serving 1250 users with a contention ratio of $4: 1$. The localization of the cells in this variant is represented in Figure 3, while brown denotes the cells in the business center. We assume a coverage of ca. $96 \%$ and interference of ca. $1.2 \%$.

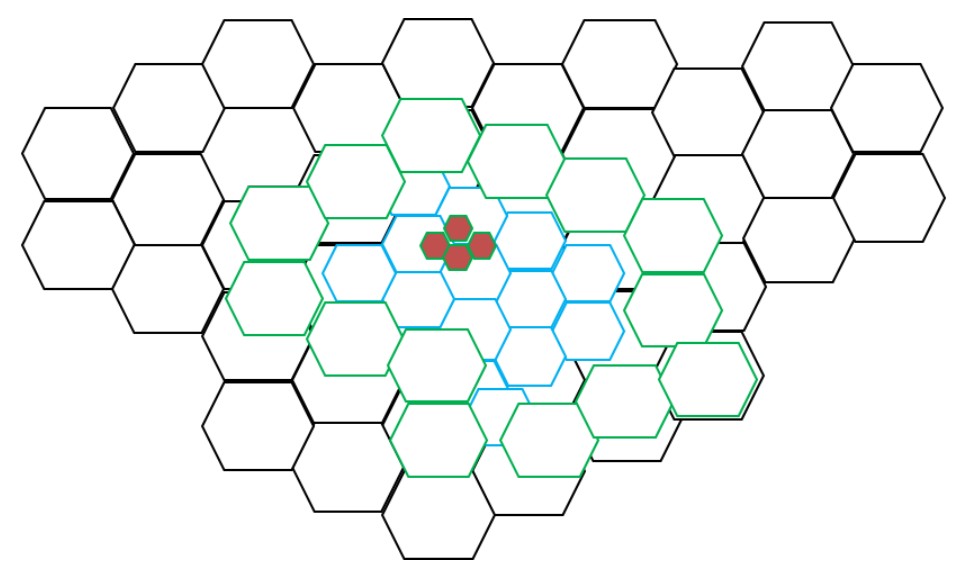

Figure 3. Localization of cells in city, suburbs, rural areas, and business center 


\section{Variant 4}

We assume here that Variant 3 was enhanced by a business center of $1.5 \mathrm{~km}^{2}$ in the suburban area. The expected density of users in this center is 2000 users per $\mathrm{km}^{2}$; thus, new cells are added. The localization of the cells in this variant is presented in Figure 4. The additional cells in the new business center are indicated by yellow; the cells in city business center - brown; urban cells - blue; suburban - green; and rural - black. There are 3 cells in the suburban business center; each can serve 1000 users. A good contention ratio of $3: 1$, and an interference of $1.3 \%$ is expected.

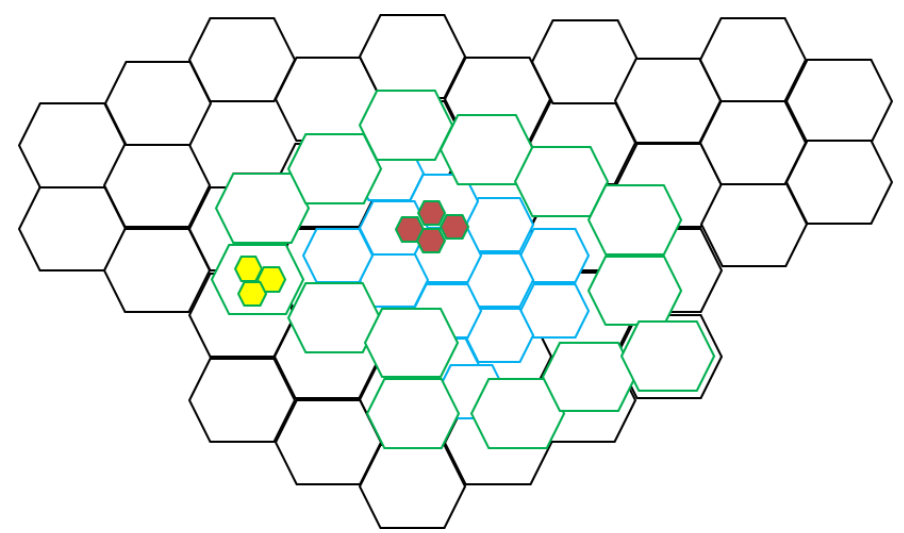

Figure 4. Localization of cells in city, suburban and rural areas, and urban and suburban business centers

\section{Variant 5}

This variant is based on Variant 4 enhanced by a new enterprise zone in an area of $10 \mathrm{~km}^{2}$ covered by 3 new cells (depicted in solid blue in Figure 5).

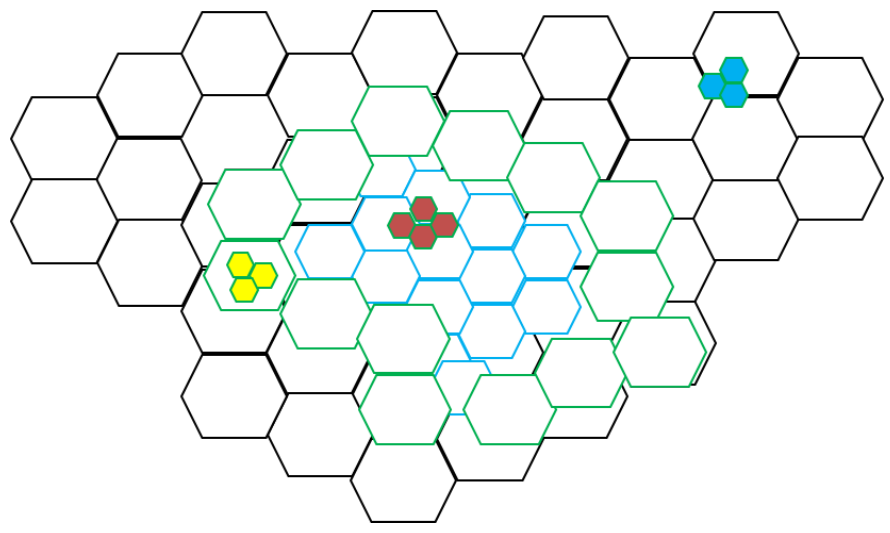

Figure 5. Localization of cells in Variant 5, including city, suburban and rural areas, city and suburban business centers, and new enterprise zone (solid blue cells) 
The expected density of users in the new zone is 300 users per $\mathrm{km}^{2}$. Each cell can serve 1000 users with a contention ratio of ca. $3: 1$. The interference is ca. $1.4 \%$, and the coverage is (as in the other variants) ca. $96 \%$.

\section{Variant 6}

This is Variant 5 enhanced in the city by a second business center of a $0.5 \mathrm{~km}^{2}$ area served by 3 new cells (depicted by solid light red in Figure 6).

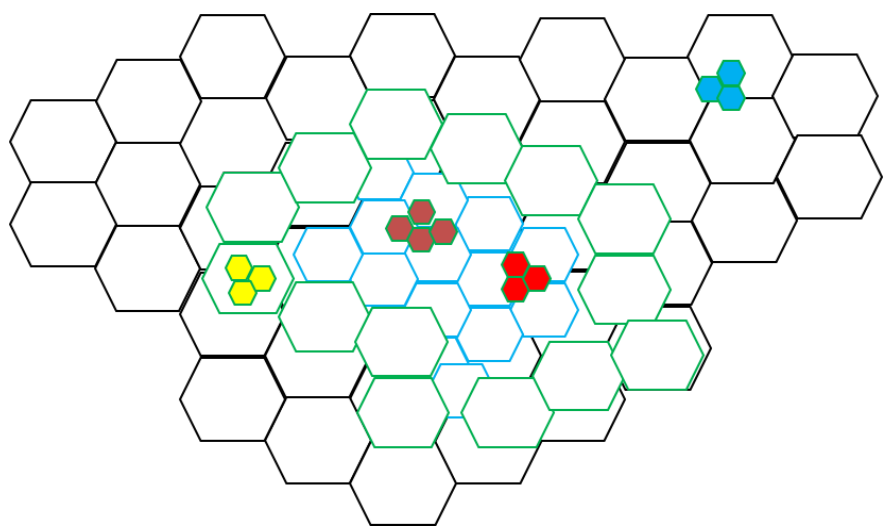

Figure 6. Localization of cells in new city business center (bright red cells), old city business center (dark red cells), city, suburban and rural areas as well as suburban business center and enterprise zone

The expected density is 6000 users per $\mathrm{km}^{2}$; hence, these 3 cells will potentially serve 3000 users each; a new technology will allow us to serve 1000 users at the same time with a contention ratio of $3: 1$. The interference is ca. $1.5 \%$, and the coverage is (as in the other variants) ca. $96 \%$.

A comparison of the variants and criteria is presented in Table 1. The values for the criterion "Coverage" are identical for all variants; hence, "Coverage" will not be used as a criterion in the rankings. The values of the criterion "Contention" ratio are different for the different areas; hence, to characterize the variants, their average weighted by the number of users was computed.

Table 1

Criteria and variants

\begin{tabular}{|l|c|c|c|c|c|c|}
\hline \multirow{2}{*}{ Criteria } & \multicolumn{7}{|c|}{ Variants } \\
\cline { 2 - 7 } & $\mathbf{1}$ & $\mathbf{2}$ & $\mathbf{3}$ & $\mathbf{4}$ & $\mathbf{5}$ & $\mathbf{6}$ \\
\hline 1. Network capacity & 27000 & 34500 & 35700 & 36600 & 37500 & 38400 \\
\hline 2. Expected number of users & & & & & & \\
\hline 1 year & 20000 & 25000 & 30000 & 33000 & 36000 & 39000 \\
\hline 2 year & 30000 & 35000 & 40000 & 43000 & 46000 & 49000 \\
\hline 3 year & 40000 & 45000 & 50000 & 53000 & 56000 & 59000 \\
\hline
\end{tabular}


Table 1 - cont.

\begin{tabular}{|l|c|c|c|c|c|c|}
\hline \multirow{2}{*}{ Criteria } & \multicolumn{7}{|c|}{ Variants } \\
\cline { 2 - 7 } & $\mathbf{1}$ & $\mathbf{2}$ & $\mathbf{3}$ & $\mathbf{4}$ & $\mathbf{5}$ & $\mathbf{6}$ \\
\hline 4 year & 50000 & 55000 & 60000 & 63000 & 66000 & 69000 \\
\hline 5 year & 55000 & 60000 & 65000 & 68000 & 71000 & 74000 \\
\hline Average per year & 39000 & 44000 & 49000 & 52000 & 55000 & 58000 \\
\hline $\begin{array}{l}\text { 3. Expected income } \\
\text { in thousands } \$\end{array}$ & & & & & \\
\hline 1 year & 1000 & 1250 & 1500 & 1650 & 1800 & 1950 \\
\hline 2 year & 1500 & 1750 & 2000 & 2150 & 2300 & 2450 \\
\hline 3 year & 2000 & 2250 & 2500 & 2650 & 2800 & 2950 \\
\hline 4 year & 2500 & 2750 & 3000 & 3150 & 3300 & 3450 \\
\hline 5 year & 2750 & 3000 & 3250 & 3400 & 3550 & 3700 \\
\hline Yearly average & 1950 & 2200 & 2450 & 2600 & 2750 & 2900 \\
\hline 4. Number of cells & 90 & 115 & 119 & 122 & 125 & 128 \\
\hline 5. Interference & $1 \%$ & $1.1 \%$ & $1.2 \%$ & $1.3 \%$ & $1.4 \%$ & $1.5 \%$ \\
\hline 6. Contention ratio & & & & & & \\
\hline Rual area & $5: 1$ & $5: 1$ & $5: 1$ & $5: 1$ & $5: 1$ & $5: 1$ \\
\hline City & $8: 1$ & $8: 1$ & $8: 1$ & $8: 1$ & $8: 1$ & $8: 1$ \\
\hline Suburban area & - & $4: 1$ & $4: 1$ & $4: 1$ & $4: 1$ & $4: 1$ \\
\hline City business centre 1 & - & - & $4: 1$ & $4: 1$ & $4: 1$ & $4: 1$ \\
\hline Suburban business centre & - & - & - & $3: 1$ & $3: 1$ & $3: 1$ \\
\hline Enterprise zone & - & - & - & - & $3: 1$ & $3: 1$ \\
\hline $\begin{array}{l}\text { City business centre 2 } \\
\text { Contention ratio } \\
\text { average weighted }\end{array}$ & - & - & - & - & - & $3: 1$ \\
\hline $\begin{array}{l}\text { 7. Investment costs } \\
\text { in thousands \$ }\end{array}$ & 7.03 & 6.57 & 6.51 & 6.46 & 6.42 & 6.37 \\
\hline in thousands \$/year & 4860 & 6210 & 6426 & 6588 & 6750 & 6912 \\
\hline
\end{tabular}

\section{Multiple criteria ranking objectified and subjective; examples of computations}

In [12], a detailed description of the objectified ranking is presented. The method relies on the reference point approach; the reference values for all criteria result from the data of the problem (that is, from the values of the criteria for all variants subjective to ranking). Based on these reference values, the values of the partial achievement functions for the criteria values and of the overall achievement functions for the subsequent variants are determined. These last values are used as a basis for ranking; hence, ranking is not based on the subjectively defined weighting coefficients but on the situation of the criteria values for a given variant compared to the criteria values for all variants. Obviously, even the choice of a ranking method is a subjective decision; hence, such a ranking (even if was originally called an objective ranking [12]) should rather be called an objectified ranking. 
In more detail, if we consider set $\boldsymbol{K}$ of criteria with the number of them $K$ and the set of decision variants $\boldsymbol{W}$ with the number of variants $W$, then for a $k$-th criterion (assuming that it is maximized), reservation level $r_{k}$ and aspiration level $a_{k}$ are determined by the following formulae:

$$
m_{k}=\sum_{w \in W} q_{k w} / W ; r_{k}=0.5\left(q_{k}^{l o}+m_{k}\right) ; a_{k}=0.5\left(q_{k}^{u p}+m_{k}\right), \forall k \in K
$$

where $q_{k w}$ is the value of the $\mathrm{k}$-th criterion for the $\mathrm{w}$-th variant and $q_{k}^{l o}=\min _{w \in W} q_{k w}$; $q_{k}^{u p}=\max _{w \in W} q_{k w}$. For minimized criteria $r_{k}=0.5\left(q_{k}^{u p}+m_{k}\right) ; a_{k}=0.5\left(q_{k}^{l o}+m_{k}\right)$. After determining these reference levels for all of the criteria, the values of the partial achievement functions for a given criterion and variant are determined as follows. For maximized criteria:

$$
\sigma_{k w}\left(q_{k w}, a_{k}, r_{k}\right)= \begin{cases}\alpha\left(q_{k w}-q_{k}^{l o}\right) /\left(r_{k}-q_{k}^{l o}\right), & \text { for } q_{k}^{l o} \leq q_{k w}<r_{k} \\ \alpha+(\beta-\alpha)\left(q_{k w}-r_{k}\right) /\left(a_{k}-r_{k}\right), & \text { for } r_{k} \leq q_{k w}<a_{k} \\ \beta+(10-\beta)\left(q_{k w}-a_{k}\right) /\left(q_{k}^{u p}-a_{k}\right), & \text { for } a_{k} \leq q_{k w} \leq q_{k}^{u p}\end{cases}
$$

where $0<\alpha<\beta<10, \alpha$ is a parameter denoting the value of the partial achievement function for $q_{k w}=r_{k}$ and $\beta$ is a parameter denoting the value of the partial achievement function for $q_{k w}=a_{k}$. For minimized criteria (where the roles of $r_{k}$ i $a_{k}$ are exchanged):

$$
\sigma_{k w}\left(q_{k w}, a_{k}, r_{k}\right)= \begin{cases}\beta+(10-\beta)\left(a_{k}-q_{k w}\right) /\left(a_{k}-q_{k}^{l o}\right), & \text { for } q_{k}^{l o} \leq q_{k w}<a_{k} \\ \alpha+(\beta-\alpha)\left(r_{k}-q_{k w}\right) /\left(r_{k}-a_{k}\right), & \text { for } a_{k} \leq q_{k w}<r_{k} \\ \alpha\left(q_{k}^{u p}-q_{k w}\right) /\left(q_{k}^{u p}-a_{k}\right), & \text { for } r_{k} \leq q_{k w} \leq q_{k}^{u p}\end{cases}
$$

The overall achievement function (whose values are used to determine the objectified ranking lists) is computed on the basis of the partial achievement functions as follows:

$$
\sigma\left(\boldsymbol{q}_{w}, \boldsymbol{a}, \boldsymbol{r}\right)=\min _{k \in \boldsymbol{K}} \sigma_{k w}\left(q_{k w}, a_{k}, r_{k}\right)+\epsilon / W \sum_{k \in \boldsymbol{K}} \sigma_{k w}\left(q_{k w}, a_{k}, r_{k}\right)
$$

where $\epsilon>0$ is a parameter of a small parameter (e.g., $(0,1-0,3) \mathrm{W})$. The ranking obtained on the basis of values $\sigma\left(\mathbf{q}_{w}\right.$, a, and $\left.\mathbf{r}\right)$ for consequent variants $w \in \boldsymbol{W}$ is called "objective" (or rather "objectified"), since it is based only on the data of the problem (the values of $q_{k w}$ for $k \in \boldsymbol{K}$ and $w \in \boldsymbol{W}$ ). Obviously, such a ranking can be easily subjectified by assuming weighting coefficients $\alpha_{k}$ for criteria $k \in \boldsymbol{K}$ and modifying Eq. (4); e.g., to the following form:

$$
\begin{gathered}
\sigma\left(\boldsymbol{q}_{w}, \boldsymbol{a}, \boldsymbol{r}\right)=\alpha_{1} \min _{k \in \boldsymbol{K} \mathbf{1}} \sigma_{k w}\left(q_{k w}, a_{k}, r_{k}\right)+\alpha_{2} \min _{k \in \boldsymbol{K} \mathbf{2}} \sigma_{k w}\left(q_{k w}, a_{k}, r_{k}\right) \\
+\epsilon / W \sum_{k \in \boldsymbol{K}} \alpha_{k} \sigma_{k w}\left(q_{k w}, a_{k}, r_{k}\right)
\end{gathered}
$$


where

$$
K=K 1 \cup K \mathscr{2}
$$

with selected values of $\alpha_{1}$ and $\alpha_{2}$; e.g., $\alpha_{1}=1, \alpha_{2}=0.2$. However, it is better to advise the decision maker (investor) to first look through the objectified ranking list and then determine which criteria are most-important to him (belonging to set $\boldsymbol{K}_{1}$ ) or to choose fully subjectively between the variants.

\section{Examples of ranking computations}

As a basis of further comparisons, we first assume that the investor is only interested in one criterion - profit. In this example, we use the expected incomes minus the operation costs during the first five years to compute the expected profits. The results are presented in Table 2.

Table 2

Values of criterion expected profits in first 5 years

\begin{tabular}{|c|c|c|c|c|c|c|}
\hline \multirow{2}{*}{ Criterion } & \multicolumn{6}{|c|}{ Variants } \\
\cline { 2 - 8 } & $\mathbf{1}$ & $\mathbf{2}$ & $\mathbf{3}$ & $\mathbf{4}$ & $\mathbf{5}$ & $\mathbf{6}$ \\
\hline Expected 5-year profit (in thousands of $\$)$ & 4890 & 4790 & 5824 & 6412 & 7000 & 7588 \\
\hline
\end{tabular}

Using only this criterion, we obtain an obvious ranking where Variant 6 is mostpreferred; this shall be called Ranking 0 . In Table 3 , the values of the corresponding achievement function values are indicated.

Table 3

Ranking 0

\begin{tabular}{|c|c|c|c|c|c|}
\hline \multicolumn{6}{|c|}{ Variants } \\
\hline $\mathbf{6}$ & $\mathbf{5}$ & $\mathbf{4}$ & $\mathbf{3}$ & $\mathbf{1}$ & $\mathbf{2}$ \\
\hline 10.166 & 7.781 & 5.884 & 4.174 & 0.471 & 0.0 \\
\hline
\end{tabular}

An objectified ranking using eight of the criteria treated as equally important gives quite different results (called Ranking 1). In Table 4, the computed achievement values for the subsequent variants are indicated.

Table 4

Ranking 1

\begin{tabular}{|c|c|c|c|c|c|}
\hline \multicolumn{6}{|c|}{ Variants } \\
\hline $\mathbf{3}$ & $\mathbf{4}$ & $\mathbf{2}$ & $\mathbf{5}$ & $\mathbf{6}$ & $\mathbf{1}$ \\
\hline 4.344 & 3.719 & 3.492 & 0.938 & 0.666 & 0.666 \\
\hline
\end{tabular}

This essential difference results from the impact of criteria such as contention ratio, interference, and investment costs that results in the preference of middle solutions. However, an investor might insist on the use of expected profits as a dominating criterion. Such a subjectified ranking might be obtained by summing the achievement 
values for Ranking 0 with weight $\alpha_{1}=1$ and for Ranking 1 with weight $\alpha_{2}=0,2$ or bigger. The results are presented in Table 5 .

Table 5

Ranking 2 with weighting coefficients $\alpha_{1}=1$ and $\alpha_{2}=0,2$

\begin{tabular}{|c|c|c|c|c|c|}
\hline \multicolumn{6}{|c|}{ Variants } \\
\hline $\mathbf{6}$ & $\mathbf{5}$ & $\mathbf{4}$ & $\mathbf{3}$ & $\mathbf{2}$ & $\mathbf{1}$ \\
\hline 10.3 & 7.962 & 6.627 & 5.043 & 0.698 & 0.604 \\
\hline
\end{tabular}

In order to escape the dominance of Variant 6 , we would have to increase weighting coefficient $\alpha_{2}$ to 1.5; this means that (at least in the assumed conditions) the profit is a dominating and the robust criterion of choice (Tab. 6).

Table 6

Ranking 2 with weighting coefficients $\alpha_{1}=1$ and $\alpha_{2}=1,5$

\begin{tabular}{|c|c|c|c|c|c|}
\hline \multicolumn{7}{|c|}{ Variants } \\
\hline $\mathbf{4}$ & $\mathbf{6}$ & $\mathbf{3}$ & $\mathbf{5}$ & $\mathbf{2}$ & $\mathbf{1}$ \\
\hline 11.462 & 11.166 & 10.691 & 9.190 & 5.238 & 1.471 \\
\hline
\end{tabular}

Further increase of weighting coefficient $\alpha_{2}$ results in the dominance of middle Variants 4 and 3 . In Table 7 , we give the results of ranking with weighting coefficients $\alpha_{1}=1$ and $\alpha_{2}=1,8$.

Table 7

Ranking 2 with weighting coefficients $\alpha_{1}=1$ and $\alpha_{2}=1,8$

\begin{tabular}{|c|c|c|c|c|c|}
\hline \multicolumn{7}{|c|}{ Variants } \\
\hline $\mathbf{4}$ & $\mathbf{3}$ & $\mathbf{6}$ & $\mathbf{5}$ & $\mathbf{2}$ & $\mathbf{1}$ \\
\hline 12.578 & 11.995 & 11.366 & 9.471 & 6.285 & 1.671 \\
\hline
\end{tabular}

\section{Essential findings}

The results of the experiments listed above can be interpreted as follows:

- The objectified ranking results in high-ranking positions for variants with wellbalanced parameters, not for variants with extreme parameters values. Thus, objectified ranking might better represent the interests of a regulatory office, not the interests of investors.

- However, it is easy to make the objectified ranking slightly more subjective by using the achievement function of form (5); such rankings might be preferable for investors.

- The use of the objectified ranking or its diverse modifications enriches the decision process and clarifies the intentions of the investor. 


\section{Conclusions}

Multiple criteria ranking can be used in the design of mobile telephony networks. The examples listed above show how to apply such a ranking. These examples are obviously some simplification of real conditions, but they can be enhanced or modified depending on the needs of the investors. An analysis of the resulting rankings and variants can help the decision maker - the investor - to choose the best solution. In the current market situation, the investments in areas of many business users are so profitable that they dominate over investments in rural or even suburban areas, while the latter are preferred by regulatory organs for social reasons. Objectified rankings suggest solutions closer to the regulatory preferences, but investors in this situation will mostly use profit as dominating criterion.

\section{Acknowledgements}

The research presented in this paper was partially supported by The Ministry of Science and Higher Education.

\section{References}

[1] Afroz F., Sandrasegaran K., Al Kim H.: Interference management in LTE downlink networks, International Journal of Wireless and Mobile Networks, vol. 7(1), pp. 91-106, 2015.

[2] Amaldi E., Capone A., Malucelli F., Mannino C.: Optimization problems and models for planning cellular networks: Handbook of optimization in telecommunications, Springer, 2006.

[3] Bezruk V.M., Chebotarova D.V.: Methods of multi-criteria optimization in planning networks of mobile communication, Kharkiv National University of Radio Electronics, 2014.

[4] Chen L.: Performance Engineering of Mobile Broadband: Capacity Analysis, Cellular Network Optimization, and Design of In-Building Solutions, Ph.D. thesis, Linköping University, 2013.

[5] Cong G.: Pico Cell Densification Study in LTE Heterogeneous Networks, M.Sc. thesis, 2012.

[6] Desalegn H.: Techno-Economic Analysis of LTE Deployment: A Case Study of Addis Ababa, Ethiopia, M.Sc. thesis, 2014.

[7] Katsianis D.: Techno-economic modeling and Long Term Evolution model, Evaluation of upgrade scenarios. Wireless LTE (Long term evolution) Business model, COST605 Summer School, Budapest. http://www.cost605.org/ cost605school2011/3-D-Katsianis-Technoeconomics-LTE.pdf.

[8] Ovando C., Perez J., Moral A.: LTE techno-economic assessment: The case of rural areas in Spain, Telecommunications Policy, vol. 39, pp. 269-283, 2015.

[9] Smura T.: Techno-economic modelling of wireless network and industry architectures, Aalto University, publication series Doctoral Dissertations 23/2012, 2012. 
[10] Syed A.: Dimensioning of LTE Network Description of Models and Tools, Coverage and Capacity Estimation of $3 G P P$ Long Term Evolution radio interference, Helsinki University of Technology, 2009.

[11] UKE: Long Term Evolution (LTE). Kolejny krok w ewolucji systemów telefonii komórkowej. https://www.uke.gov.pl/files/?id_plik=7099.

[12] Wierzbicki A.: The problem of objective ranking: foundations, approaches and applications, Journal of Telecommunications and Information Technology, vol. 3, pp. 15-23, 2008.

[13] Zareen U.: LTE-Advanced: Techno Economical Perspective, Universal Journal of Communications and Network, vol. 2(6), pp. 93-100, 2014.

\section{Affiliations}

\section{Edward Klimasara}

National Institute of Telecommunications, Warsaw, Poland, e.klimasara@itl.waw.pl

\section{Andrzej P. Wierzbicki}

National Institute of Telecommunication, Warsaw, Poland, a.wierzbicki@itl.waw.pl

Received: 28.08.2017

Revised: 18.12.2017

Accepted: 18.01.2018 